\title{
Efficacy of In-field Thermotherapy in Comparison and Combination of Defoliation for Mitigating Huanglongbing in Sweet Orange
}

\author{
Tripti Vashisth and Taylor Livingston \\ Citrus Research and Education Center, University of Florida/IFAS, 700 \\ Experiment Station Road, Lake Alfred, FL 33850
}

Additional index words. citrus, citrus greening, CLas, HLB

\begin{abstract}
Huanglongbing (HLB), a bacterial disease, is one of the most destructive citrus diseases. For many decades, it has been known that using heat/high temperatures (thermotherapy) is effective in suppressing plant diseases, particularly the suppression of Candidatus Liberibacter ( $C$ Las, casual agent for HLB) when the treated plants are grown in pots (allowing treatment of roots) under controlled conditions. However, in-field thermotherapy has yielded inconsistent results: the tree shows vigorous and symptomless growth for a brief period and then relapses with HLB symptoms. To understand why, this 2-year study was conducted to evaluate the efficacy of in-field thermotherapy and its comparison with defoliation. A significant reduction in visible tree health, foliage, and yield was observed over time in all the treatments. The quantitative real-time polymerase chain reaction (qRT-PCR) results showed that in-field thermotherapy and other treatments were not effective in reducing $C$ Las titer. Interestingly, the performance of thermotherapy and partial defoliated trees were comparable throughout the course of the experiment, indicating that the short-term effects and vigorous growth after thermotherapy are likely an artifact of defoliation and should not be confused with or considered recovery from disease. In an in-depth molecular and biochemical analysis, we found a few subtle transient (up to 15 days) differences occurring in the in-field thermotherapy trees. Genes associated with stress and plant defense response were observed to be altered by in-field thermotherapy. Overall, our results indicate that infield thermotherapy is not an effective and reliable strategy for mitigating HLB in commercial citrus production and that its efficacy within in-field conditions is similar to manual defoliation. It is critical that any strategy aimed at mitigating HLB should target the whole plant, including the roots, as the $C$ Las colonizes in shoots and the root system; therefore, it can possibly translocate within the entire plant with the bulk phloem flow.
\end{abstract}

Huanglongbing (HLB, aka citrus greening), a bacterial disease caused by Candidatus Liberibacter asiaticus (CLas), threatens citrus production in Florida and around the world (Alvarez et al., 2016; Bové, 2006). HLB can be transmitted by grafting with an infected citrus budwood or via a citrus pest, Asian citrus psyllid, a natural vector of this disease and the most common way HLB is spread (Bové, 2006). Asian citrus psyllid feeds on the young leaves of citrus, and during the feeding process, it can transmit

\footnotetext{
Received for publication 18 Oct. 2019. Accepted for publication 3 Dec. 2019

Published online 14 January 2020.

We thank Tony Trama, Florida Department of Citrus for technical support in carbohydrate analysis and Premier Energy (Florida) for their technical support in-field thermotherapy treatment. Funding for this project was made possible by State Legislative funding for the UF/IFAS Citrus Initiative.

T.V. is the corresponding author. E-mail: tvashisth@ ufl.edu.

This is an open access article distributed under the CC BY-NC-ND license (https://creativecommons. org/licenses/by-nc-nd/4.0/).
}

or acquire the bacteria to/from the leaf. Psyllids also lay eggs on young citrus leaves; and, as the nymphs grow, they acquire the bacteria from infected leaves (Halbert and Manjunath, 2004), thereby becoming capable of infecting other trees during its lifecycle.

$C$ Las, the causal agent of HLB, is a phloem-limited bacterium and can translocate within the plant due to the movement of phloem (Bové, 2006). Johnson et al. (2014) reported that HLB-affected trees often suffer significant root loss, and the CLas presence can be detected in the root system even before visible symptoms appear on the tree, suggesting that CLas first colonizes in roots due to bulk phloem flow. Once infected by CLas, plugging in phloem sieve pores can be observed, resulting in an accumulation of starch in symptomatic leaves (Kim et al., 2009; Schneider, 1968), the aerial stem, and bark tissue (Etxeberria et al., 2009). Typical visible symptoms of HLB-affected trees include yellowing of leaves, and blotchy and/or chlorotic patterns of leaves induced by zinc and iron deficiencies (Bové, 2006). Leaves become small and upright, similar to drought stress symptoms. In HLB-affected trees, the disruption of vascular function, loss of root system, and altered mineral nutrition lead to arrested plant and fruit growth and decline in the production (Bové, 2006; Halbert and Manjunath, 2004). Fruit produced by HLBaffected trees are often small, lopsided, poorly colored, contain aborted seeds, and drop prematurely (Graca, 1991). Rosales and Burns (2011) demonstrated that HLB symptomatic fruits were low in starch and sucrose as compared with asymptomatic or healthy fruit, suggesting that the carbohydrate deficiency contributes to the small size and poor fruit growth and development.

Currently, there is no cure for HLB, and all the varieties of citrus are susceptible to it; hence, all the existing groves and new plantings are also susceptible. It has been known for decades that the application of heat/high temperatures can suppress plant diseases. In a review of postharvest diseases by Eckert and Sommer (1967), it was reported that as early as the 1920 s, citrus packers were using hot water to improve shelf life of fruit and quell diseases. Such treatment of heat is often referred to as thermotherapy and has been reported to be effective against pathogenic microorganisms like viruses, bacteria, fungi, etc. (Grondeau et al., 1994). The principle of thermotherapy is that "parasitic microorganisms often are killed, or viruses inhibited, at temperature time regimes only slightly injurious to the host" (Baker, 1962). Therefore, high temperatures (sublethal to plants but lethal to microorganisms) can be used to eradicate the disease or reduce the inoculum in the host. In 1965, it was demonstrated that hot air could be used for suppressing HLB (Lin and Lo, 1981). Lo et al. (1981) reported the use of hot air $\left(49\right.$ to $\left.50{ }^{\circ} \mathrm{C}\right)$ for 50 to $60 \mathrm{~min}$ resulted in complete eradication of bacteria in HLB-affected plants. Since the advent of HLB in Florida, a number of researchers have recently been exploring the potential of thermotherapy to treat HLBaffected trees. Hoffman et al. (2013) reported that continuous exposure of seedlings (including roots) grafted with CLas-positive buds at $40{ }^{\circ} \mathrm{C}$ for $2 \mathrm{~d}$ was sufficient to suppress the $C$ Las in newly emerged leaves of seedlings. In another greenhouse study, 2-year-old potted citrus plants were found to become $C$ Las negative when the entire plant was exposed to 45 to $48{ }^{\circ} \mathrm{C}$ for $4 \mathrm{~h}$ once a week for 3 consecutive weeks (Fan et al., 2016). It should be noted that, in both the aforementioned studies, the plants were placed in a growth chamber where the entire plant (including roots) was treated with heat. Conversely, under field conditions, continuous exposure to high heat did not eradicate the CLas in mature citrus trees (Doud et al., 2017), but even so, trees showed vigorous vegetative growth. They speculated that the inability to heat-treat the root system might be one of the major reasons for these results. However, the emergence of vigorous and symptomless vegetative growth following the heat treatment has been a common observation, suggesting improvement in tree conditions even though the tree remains infected (Doud et al., 2017). Thermotherapy 
results in significant immediate leaf loss (Fan et al., 2016; Schumann and Singerman, 2016), although the extent of leaf loss depends on the time temperature combination as well as equipment used for treatment; for example, when the tree is heat-treated for multiple days at mild temperatures using a steam chamber, a complete leaf loss can be seen, whereas when treated in the field at high heat for short duration, a partial leaf loss can be observed. On the other hand, vigorous vegetative growth following a pruning or defoliation treatment is a common observation in citrus (Eissenstat and Duncan, 1992; Phillips, 1978). Consequently, it is likely that the new growth emergence is a result of defoliation instead of bacteria suppression by in-field thermotherapy. A number of growers in Florida have been exploring thermotherapy to improve tree growth and productivity, but the results are not conclusive. Therefore, the objective of this study was to compare the efficacy of thermotherapy with manual defoliation for suppression of $C$ Las and to improve the growth and productivity of HLB-affected trees. Combination treatments of thermotherapy and defoliation were also evaluated with the hypothesis that leaf loss caused by defoliation or thermotherapy would result in remobilization of the CLas colonized in roots to the shoot system with bulk phloem flow to support new growth. Hence, a follow-up thermotherapy or defoliation can eliminate the CLas from the whole plant. Parameters considered in this study were canopy volume and density, $C$ Las titer, yield, leaf carbohydrates, and gene expression of a subset of genes.

\section{Materials and Methods}

Plant material, treatments, and experimental design. Nine-year-old trees of sweet orange cultivar, Valencia, on rootstock Swingle were used in this study. The trees were grown at a research block in Lake Alfred, FL, under standard commercial production practices for fertilization, irrigation, and pests and disease control. The soil type was sandy with $\mathrm{pH}$ ranging from 6.5 to 7.0 . All the trees used in this study were HLB symptomatic and $C$ Las positive, as confirmed by qRT-PCR (method explained in the next section). The experimental setup was a completely randomized block design $(n=4)$, where five trees were considered as one experimental unit. The following eight treatments were evaluated in this experiment: Control (untreated), $100 \%$ Defoliation (DF 100\%), Thermotherapy (TT), 100\% Defoliation followed by thermotherapy (DFTT), 100\% Defoliation followed by Thermotherapy in 6 weeks (DFTT 6), Thermotherapy followed by thermotherapy in 6 weeks (TTTT 6), 100\% Defoliation followed by $100 \%$ defoliation in 6 weeks (DFDF 6), and 50\% Defoliation (DF $50 \%$ ). Defoliation was performed by removing the leaves by hand. For $100 \%$ defoliation, all of the leaves from the tree were removed; and, for $50 \%$ defoliation, every other leaf was removed from every branch. Only two levels of defoliation were considered in this experiment, as it is difficult to truly defoliate a tree at a particular level other than $100 \%$ and $50 \%$; and also, as the extent of in-field thermotherapy has not been previously estimated. A commercial company, Premier Energy (Dundee, FL), performed in-field thermotherapy treatment (Supplemental Fig. 1). For the thermotherapy treatments, the trees were covered with a large fabric canopy supplemented with fans and steam pipes to distribute heat/steam evenly. The trees were exposed to $55^{\circ} \mathrm{C}$ for $30 \mathrm{~s}$. It took $\approx 2.5 \mathrm{~min}$ to ramp up the temperature to $55^{\circ} \mathrm{C}$; hence, the thermotherapy treatment took $\approx 3$ min per treatment per tree. The treatments were performed in April 2016 and June 2016 (6week posttreatments for DFTT 6 and TTTT 6). Because these were 'Valencia' trees, the maturing fruit from fruit set of previous year were harvested before initiation of experiments. The trees were monitored until April 2018.

CLas quantification. Leaf samples were randomly collected. The midribs of the leaves were excised and stored at $-80{ }^{\circ} \mathrm{C}$ until DNA extraction. DNA extraction was performed using DNeasy Plant Kits (Qiagen, Valencia, CA) as per the manufacturer's instructions and qRT-PCR was performed using rpoB primer (Ananthakrishnan et al., 2013):

\section{Forward: TGAGGAGAAACGATGGCA-} AAAGGC

Reverse: GACATACCTGATCTCATTGAAGTTCAG

Probe: TTGTGTTCAATGGTCTCGGGCG

The qRT-PCR results are represented as the cycle threshold ( $\mathrm{Ct}$ value). The CLas quantification was done pretreatment, and 3 , 6 , and 12 months posttreatment (MPT).

Visual HLB disease index rating. Each tree canopy hemisphere was scored individually on a 0 to 5 scale indicative of the proportion of limbs expressing HLB disease symptoms within each section $(0=$ no limbs, $5=$ all limbs). The average of the two scores for each tree was used to rate the disease index (DI) for each tree per survey date. DI was calculated pretreatment, and 3,6,12, and 24 MPT.

Canopy volume measurement. Canopy volumes were measured pretreatment, and 6, 12, and 24 MPT. Canopy volumes are expressed as $\mathrm{m}^{3}$ and were calculated using the following geometric prolate spheroid formula:

$$
\left[(4 / 3)(\pi)(\mathrm{H} / 2)(\mathrm{ACR})^{2}\right]
$$

where $\pi=3.14, \mathrm{H}=$ tree height, and ACR = average canopy radius. ACR was calculated by dividing the tree diameter by two. Tree diameter was measured in two directions: east to west (D1) and north to south (D2).

Canopy density. Canopy density was assessed by measuring leaf area index (LAI) from the middle of the canopy. LAI was measured by plant canopy analyzer CI-110 (CID Bio-Science, Camas, WA). The measurements were done around noon and when the sky was free of clouds. LAI was measured pretreatment, and 6 and $24 \mathrm{MPT}$. The 12 MPT timepoint was missed because of some technical issues with the equipment.

Fruit yield. Fruit yield was measured for two consecutive years in 2016-17 and 2017-18. All the trees were manually harvested when the fruit reached commercial maturity standard (approximately March end/early April). Maturity status of fruit was determined by measuring total soluble solids and titratable acidity using a pocket refractometer (Atago USA, Inc., Bellevue, WA).

Gene expression analysis. Gene expression analysis was performed for the following treatments: control, $50 \%$ defoliation, and thermotherapy. Pretreatment, and 15, 60, and $180 \mathrm{~d}$ posttreatment (DPT) fully expanded leaves were collected, immediately frozen in liquid nitrogen, and stored at $-80{ }^{\circ} \mathrm{C}$. Total RNA was extracted using RNeasy Plant Mini Kit (Qiagen, Hilden, Germany). The quality and quantity of RNA were evaluated by spectrophotometry using an Epoch 2 Microplate Spectrophotometer (BioTek Instruments, Inc., Winooski, VT) and with denaturing formaldehyde $1.2 \%$ agarose gels. Before complementary DNA (cDNA) synthesis, potential genomic DNA contamination was removed by treating $1 \mu \mathrm{g}$ of the total RNA with DNase $\left[37^{\circ} \mathrm{C}\right.$ for 34 min (Promega Corp., Madison, WI)]. The DNase-treated RNA was reverse transcribed using ImProm-II Reverse Transcriptase (Promega Corp.) and oligo (dT) in a $20-\mu \mathrm{L}$ reaction volume. Reverse transcription was performed at $42{ }^{\circ} \mathrm{C}$ for $75 \mathrm{~min}$, followed by incubation at $75^{\circ} \mathrm{C}$ for $15 \mathrm{~min}$. The cDNA samples were subsequently diluted 10 -fold and stored at $-20{ }^{\circ} \mathrm{C}$ until further analysis. Gene expression analysis was performed using qRT-PCR. Fourteen genes related to plant defense response, phytohormone metabolism and signaling, and carbohydrate metabolism were used. The list of genes with their Arabidopsis homologs, primer sequence, and amplicon size used in this study are presented in Table 1. Primers were designed either manually or using PrimerQuest (Integrated DNA Technologies, Coralville, IA). All qRT-PCR reactions were performed using a real-time PCR system (Fast 7500 cycler; Applied Biosystems, Foster City, CA). A reaction volume of $10 \mu \mathrm{L}$ with $1 \mu \mathrm{L}$ of cDNA, $2 \mu \mathrm{L}$ forward and reverse primer $(0.3 \mu \mathrm{M})$, and $5 \mu \mathrm{L}$ of PowerUp SYBR Green Master Mix (2X) (Applied Biosystems) was used. Each reaction was run at $50{ }^{\circ} \mathrm{C}$ for $2 \mathrm{~min}$ and $95^{\circ} \mathrm{C}$ for $2 \mathrm{~min}$ followed by 40 cycles of $95{ }^{\circ} \mathrm{C}$ for $3 \mathrm{~s}$ and $60{ }^{\circ} \mathrm{C}$ for $30 \mathrm{~s}$. Dissociation-curve analysis ranging from 60 to $95^{\circ} \mathrm{C}$ was run at the end of each qPCR run to confirm that nonspecific products were not formed. Control reactions without a template and the reverse transcriptase were performed for each gene. The primer efficiency (E) for each gene was determined using LinRegPCR 
Table 1. List of genes for quantitative real-time polymerase chain reaction analysis with primer sequences, Arabidopsis homolog ID, and amplicon size.

\begin{tabular}{|c|c|c|c|c|}
\hline Gene name & Description & Arabidopsis thaliana_ID & Primer pair sequences & Amplicon size (nt) \\
\hline $2 O G-F e(I I)$ & $\begin{array}{l}\text { 1-aminocyclopropane-1-carboxylate } \\
\text { oxidase 5-like }\end{array}$ & AT4G10490 & $\begin{array}{l}\text { F: GGACTTGACGAACGTTGCTT } \\
\text { R: ATCAAGCAGCATGAAGCTTTG }\end{array}$ & 127 \\
\hline$J M T$ & Salicylate carboxymethyl transferase & AT3G11480 & $\begin{array}{l}\text { F: AGAGGAAGCCATGACCAAAC } \\
\text { R: TAATTGACTGCCCAACTTATCGCA }\end{array}$ & 154 \\
\hline$C A B / E L I P$ & $\begin{array}{l}\text { Chlorophyll A-B binding family } \\
\text { protein/early light-induced } \\
\text { protein (ELIP) }\end{array}$ & AT3G22840 & $\begin{array}{l}\text { F: TGACTTCGGATGCTGAGTTG } \\
\text { R: AGCCACGGAAGAAACATGAC }\end{array}$ & 200 \\
\hline$C D R 1$ & Aspartic proteinase CDR1-like & AT5G33340 & $\begin{array}{l}\text { F: ATTATGGCGACCTTCTTGAGTTG } \\
\text { R: ATCGTTGGTAGGGAGTTTCAC }\end{array}$ & 163 \\
\hline$M P C 1$ & Mitochondrial pyruvate carrier 1-like & AT5G20090 & $\begin{array}{l}\text { F: CTTCCCTTTGCCGCATTTTT } \\
\text { R: CACAACGCAGAATATACACACATC }\end{array}$ & \\
\hline CALS12 & Callose synthase 12 & AT4G03550 & $\begin{array}{l}\text { F: TATCTGGCTCTTAGTGGTATAG } \\
\text { R: TCTCCACAATCATAGGTAGG }\end{array}$ & 133 \\
\hline$G P T$ & $\begin{array}{l}\text { Glucose-6-phosphate/phosphate } \\
\text { transporter }\end{array}$ & AT1G61800 & $\begin{array}{l}\text { F: GCGGCACAGAGTATCTTCTATC } \\
\text { R: CAAGAGCATTGACGGGTTGAACT }\end{array}$ & 166 \\
\hline$A C T 7$ & Actin-7 & AT5G09810 & $\begin{array}{l}\text { F: GTTGGTTGACATGGAGAAG } \\
\text { R: GACGGTTGAGTACAGAAATAAG }\end{array}$ & 121 \\
\hline DIMI & Thioredoxin-like protein YLS8 & AT5G08290 & $\begin{array}{l}\text { F: CGAAACCTGTATGCAGATGG } \\
\text { R: ACGGTTGAGGGATCGTAAAG }\end{array}$ & 138 \\
\hline
\end{tabular}

$\mathrm{F}=$ forward $\mathrm{R}=$ reverse.

(Ramakers et al., 2003; Ruijter et al., 2009). Relative expression was calculated using a modified Pfaffl method (Pfaffl, 2001), control pretreatment was used for calculating relative expression. ACTIN (ACT) (accession no. XM_006464503.2) and a DIM1 homolog/YLS8 (accession no. XM 006484463.2) were used as the reference genes (Mafra et al., 2013). The geometric mean of expression of these two reference genes (normalization factor) was used for normalization.

Carbohydrate quantification. For pretreatment, and 15, 60, and 180 DPT, glucose, fructose, sucrose, and inositol were quantified in leaves (control, TT, DF 50) using ion chromatography (IC). For extraction and quantification, the Cataldi et al. (2000) protocol was used, with some modifications. One gram of ground leaf tissue was suspended briefly into deionized water. For efficient extraction, the samples were sonicated for $15 \mathrm{~min}$ in an ultra-sonic water bath (Branson, Danbury, CT) and then centrifuged at 12,000 $g_{\mathrm{n}}$ for $5 \mathrm{~min}$. The aqueous phase was collected and filtered through two prefilled chromatography columns to remove anion (1-X8 resin; Bio-Rad, Hercules, CA) and cation (50W-X8 resin; Bio-Rad) contaminants. Two hundred and fifty microliters of filtered sample was transferred to a $0.45-\mu \mathrm{m}$ PTFE filter vial (Restek, Bellafonte, PA), and filtered again. Twenty-five microliters of elute was injected into an ICS-3000 (Dionex, Sunnyvale, CA) equipped with CarboPac MA1 anion exchange column $(250 \mathrm{~mm} \times$ $4 \mathrm{~mm})$ with a guard column $(50 \mathrm{~mm} \times 4 \mathrm{~mm})$
(Dionex). An isocratic mobile phase consisting of solvent $\mathrm{A}$ and solvent $\mathrm{B}, 38.8 \%$ deionized water, and $61.2 \% \mathrm{NaOH}(1 \mathrm{~N})$, respectively, at a flow rate of $0.4 \mathrm{~mL} / \mathrm{min}$ was used. The results are reported in milligrams per gram of leaf (fresh weight).

Statistical analysis. All statistical analyses were performed using SigmaPlot (version 11; Systat Software, San Jose, CA) software. Because this was a multiple season study that spanned over 2 years, the treatments were compared within each timepoint using one-way analysis of variance with an alpha significance level, $\alpha=0.05$. The mean separation among treatments with significant differences was performed using Tukey's honestly significant difference test.

\section{Results}

CLas quantification. The CLas titer in the leaves of untreated trees stayed the same throughout the course of study. No significant reduction in CLas titer was observed as a result of thermotherapy or other treatments (Table 2) at any timepoint. Some fluctuation in CLas titer was observed during various sampling timepoints; however, CLas titer was not significantly different between untreated trees and seven treatments at either sampling timepoints $(0,3,6$, and 12 MPT). The $\mathrm{Ct}$ value ranged from 27 to 35 , with an overall average of 32 .

Visual HLB DI rating. Visual DI rating is a good indicator of tree health and is commonly used by researchers and growers to assess overall tree health. According to this method, a lower rating indicates better tree health. At the beginning of the experiment, all the trees were assessed with similar ratings, ranging from 2.5 to 3.1 (Table 2). With the progression of time, the visual DI rating increased, indicating a decrease in tree health status. Significant differences in the visual disease rating were observed at 3 and $6 \mathrm{MPT}$ (Table 2), where untreated trees had a low rating. Overall, complete defoliation treatments (DF; alone or in combination) resulted in a severe decline of tree health within 3 MPT, whereas DF 50\%, TT, and TTTT 6 were rated similar to control at 3 and 6 MPT. Interestingly, TT treatment declined more sharply than control, DF $100 \%$, DFDF 6, DFTT 6 , and DFTT were rated poor performers at $6 \mathrm{MPT}$. Irrespective of treatments, all the trees were rated similar within 12 MPT, indicating a gradual decline in tree health as the trees continued to grow in HLBprevalent conditions. The tree rating did not change from 12 to 24 MPT (Supplemental Fig. 2)

Canopy volume measurement. No significant differences in canopy volume were observed among any treatments at any timepoint (Table 3 ). However, a steady increase in canopy volume was observed in all the trees within 24 MPT, where the average canopy volume increased from $6.5 \mathrm{~m}^{3}$ to $8 \mathrm{~m}^{3}$. This increase was unrelated to the treatments.

Canopy density. In the case of HLB, canopy density is often a better indicator of tree growth as compared with canopy volume. One of the most common HLB 
Table 2. Average cycle threshold $(\mathrm{Ct})$ value for Candidatus Liberibacter asiaticus and visual disease index rating of 9-year-old 'Valencia' on Swingle trees at pretreatment, and 3, 6, 12, and 24 months posttreatment (MPT). The treatments performed were as follows: Control (untreated), 100\% Defoliation (DF 100\%), Thermotherapy (TT), 100\% Defoliation followed by thermotherapy (DFTT), 100\% Defoliation followed by Thermotherapy in 6 weeks (DFTT 6 ), Thermotherapy followed by thermotherapy in 6 weeks (TTTT 6), 100\% Defoliation followed by $100 \%$ defoliation in 6 weeks (DFDF 6 ), and 50\% Defoliation (DF 50\%).

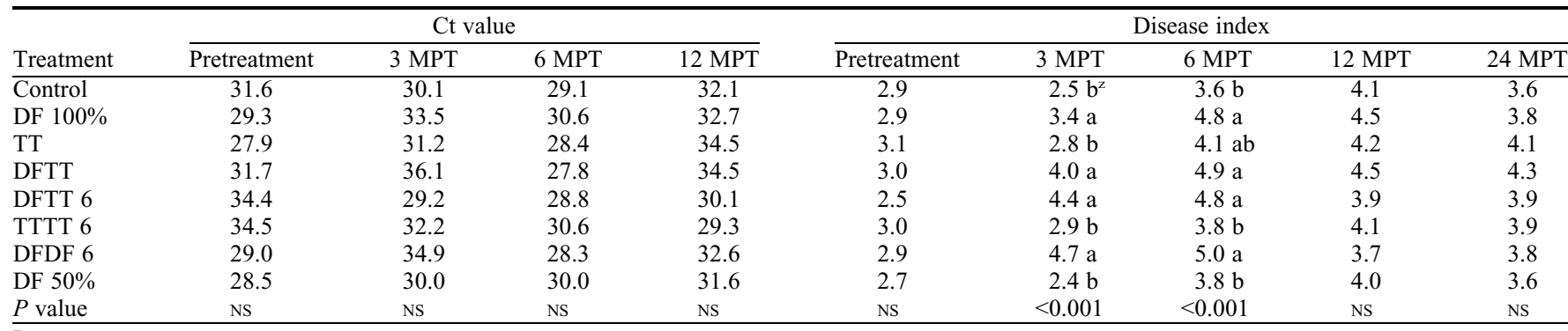

${ }^{\mathrm{z}}$ Means followed by different lowercase letters indicate statistically significant differences among treatments within timepoint using Tukey's honestly significant difference test at $\alpha=0.05$. NS $=$ not significant $(P>0.05)$.

Table 3. Average canopy volume and leaf area index (indicator of canopy density) of 9-year old 'Valencia' on Swingle trees at pretreatment, and 3, 6, 12, and 24 months posttreatment (MPT). The treatments performed were as follows: Control (untreated), $100 \%$ Defoliation (DF $100 \%)$, Thermotherapy (TT), 100\% Defoliation followed by thermotherapy (DFTT), $100 \%$ Defoliation followed by Thermotherapy in 6 weeks (DFTT 6), Thermotherapy followed by thermotherapy in 6 weeks (TTTT 6), 100\% Defoliation followed by $100 \%$ defoliation in 6 weeks (DFDF 6), and $50 \%$ Defoliation (DF $50 \%$ ).

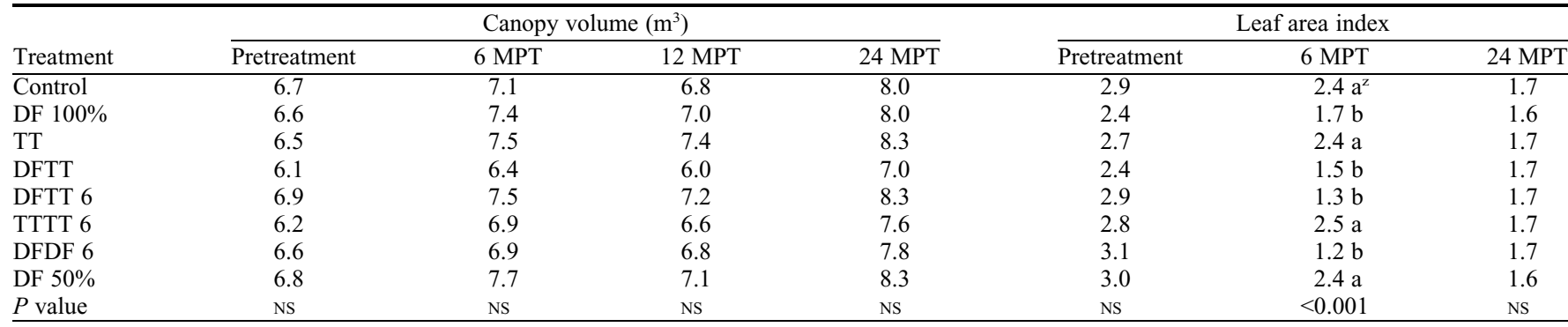

${ }^{\mathrm{z}}$ Means followed by different lowercase letters indicate statistically significant differences among treatments within timepoint using Tukey's honestly significant difference test at $\alpha=0.05$. NS $=$ not significant $(P>0.05)$.

symptoms is a thinning canopy; therefore, LAI is typically a more reliable parameter when assessing tree growth. LAI, as the name suggests, is an index calculated by accounting leaf density and photosynthetically active radiation penetrating the canopy. In this experiment, pretreatment LAI was similar for all the trees ranging from 2.4 to 3.1 (Table 3 ). Within 6 MPT all of the treatments, including DF $100 \%$, showed a significant decrease in LAI, suggesting a decline in tree health. LAI for DF 50\%, TT, and TTTT 6 did not vary as compared with control trees. This observation was similar to the visual DI rating at 6 MPT, where DF 50\%, TT, and TTTT 6 showed no significant differences as compared with control trees. It was noted that a subtle decline in LAI was observed for all the treatments. Overall, all the trees had similar LAI within 24 MPT, $\approx 1.7$, regardless of treatment. These results suggest an overall decline in tree density when HLB is prevalent.

Fruit yield. The untreated trees yielded 25.5 and $27.5 \mathrm{~kg}$ of fruit in the firstand second-year posttreatment, respectively (Table 4). As expected, a significant reduction in yield for all the treatments occurred in the subsequent year (12 MPT, Table 4). The most severe reduction in yield was observed in the treatments involving DF $100 \%$, followed by treatments including TT; the least effect on yield was observed in DF $50 \%$. These results also correspond to DI rating and canopy density data. The tree yields improved for all the treatments in year 2 and all the treatments except DF $100 \%$ and DF $50 \%$ were significantly lower than control. Overall, the yield for the 10-year-old control trees was significantly low when compared with historical data: $\approx 100 \mathrm{~kg}$ of fruit was considered average for a 10-year-old Valencia tree (Savage, 1960). Such a reduction on tree productivity is most likely an impact of HLB.

Gene expression analysis. Based on the field data observation, only three treatments were selected for in-depth gene expression and carbohydrate quantification (presented in the next paragraph): Control, TT, and DF $50 \%$, as TT and DF $50 \%$ were comparable in terms of leaf loss and overall tree performance. A total of 14 genes at four timepoints $(0,15,60$, and 180 DPT $)$ were analyzed for gene expression analysis. Of 14 genes, four genes, $C A B, M P C 1, L O X 2$, and ERF1, showed a significant expression at 15 and/or 60 DPT (Fig. 1), but all the treatments had similar gene expression by 180 DPT. Carbohydrate metabolism-related genes, such as $G P T, S U S 1, S U T 1$, and $S B 1$, were not altered as a result of treatment or sampling time. Nevertheless, plant defense response and stress-related genes, such as CDR1, JMT, $P P 2,2 O G-F e(I I)$, and $C A L S$, were found to change in expression over time, but there was no effect of treatment at any timepoint (data not shown).
Carbohydrate quantification. Glucose, fructose, inositol, sucrose, and total carbohydrates were measured in the leaves of control, $\mathrm{TT}$, and DF $50 \%$ trees at $0,15,60$, and 180 DPT (Table 5). No significant effect of treatments was observed for glucose, fructose, and inositol concentration in leaves. A significant effect of treatment was observed for sucrose and total sugar, where TT resulted in an increase in sucrose and total carbohydrate content in leaves at $15 \mathrm{DPT}$ when compared with control. DF $50 \%$ did not result in any carbohydrate content alterations and was observed to be of similar quantity to control for all timepoints. A point of interest here is that the glucose, fructose, and inositol concentrations changed in leaves with time where 60 DPT (month of June) had the highest concentration of these carbohydrates, irrespective of the treatment.

\section{Discussion}

Citrus growers are desperately looking for strategies to improve citrus production under HLB-prevalent conditions. Thermotherapy has successfully shown to reduce CLas titer in the controlled conditions when the entire plant is treated (Hoffman et al., 2013; Lin and Lo, 1981). From the outlook, the concept of in-field thermotherapy seems promising, owing to the fact that thermotherapy-treated trees produce good and healthy looking flush within a few weeks, as reported by Doud et al. 
(2017), and citrus growers. However, relapse of HLB symptoms in treated trees is commonly observed in groves (grower communication) and has led to questions regarding the efficacy of in-field thermotherapy. Over-

Table 4. Average yield (kg) in 2016-17 and 2017-18 for 'Valencia' on Swingle trees. The treatments performed were as follows: Control (untreated), $100 \%$ Defoliation (DF 100\%), Thermotherapy (TT), $100 \%$ Defoliation followed by thermotherapy (DFTT), 100\% Defoliation followed by Thermotherapy in 6 weeks (DFTT 6), Thermotherapy followed by thermotherapy in 6 weeks (TTTT 6), 100\% Defoliation followed by $100 \%$ defoliation in 6 weeks (DFDF 6), and 50\% Defoliation (DF 50\%).

\begin{tabular}{lcc}
\hline Treatment & $2016-17$ & $2017-18$ \\
\hline Control & $25.4 \mathrm{a}^{\mathrm{z}}$ & 27.5 \\
DF $100 \%$ & $1.8 \mathrm{c}$ & 25.3 \\
TT & $11.2 \mathrm{~b}$ & 16.4 \\
DFTT & $0.45 \mathrm{c}$ & 10.3 \\
DFTT 6 & $4.82 \mathrm{c}$ & 16.5 \\
TTTT 6 & $11.5 \mathrm{~b}$ & 17.8 \\
DFDF 6 & $1.5 \mathrm{c}$ & 19.8 \\
DF 50\% & $16.2 \mathrm{~b}$ & 21.9 \\
$P$ value & 0.007 & $\mathrm{NS}$ \\
\hline
\end{tabular}

${ }^{\mathrm{z}}$ Means followed by different lowercase letters indicate statistically significant differences among treatments within year using Tukey's honestly significant difference test at $\alpha=0.05$. NS $=$ not significant $(P>0.05)$. all, our results demonstrate that thermotherapy and defoliation (especially 50\%) had similar effects on tree health. The CLas titer was not observed to decrease in any of the treatments, including thermotherapy. This leads to three possibilities: 1) In-field thermotherapy treatment of $55^{\circ} \mathrm{C}$ for 3 min was not sufficient to reduce CLas titer, 2) reinfection by psyllid infestation (Li et al., 2019), and 3 ) in-field thermotherapy or defoliation of infected leaves was applied only to the aboveground canopy of the tree, meaning the CLas colonizing the root (Johnson et al., 2014) was unaffected. It is widely accepted and known that once any kind of defoliation, or loss of canopy or spring growth, occurs, roots act as a major source for carbohydrates to support new growth (Eissenstat and Duncan 1992; Loescher et al., 1990), in this case, possibly transporting the CLas along with carbohydrates. In this study, treatments with follow-up defoliation or thermotherapy (DFTT, DFTT 6, TTTT 6, and DFDF 6) were designed to address the possibility of $C$ Las movement from the structural and feeder root to shoot, buds, and new vegetative flush of the tree along with bulk phloem flow after a defoliation or thermotherapy. Thus, a follow-up thermotherapy can suppress the $C$ Las potentially present in the remobilized phloem. We did not see any significant re- duction in CLas titer for these treatments either. Although the trees in this study were regularly sprayed with insecticide, there was visible psyllid infestation on the new flush that emerged posttreatment. It has recently been found that the Asian citrus psyllid has developed resistance to common insecticides (Langdon et al., 2018). Therefore, under such situations, it becomes nearly impossible to control infection from widespread psyllid infestation. Within 6 months, the combination treatments (DFTT, DFTT 6, TTTT 6, DFDF 6) resulted in reduced tree health, as indicated by DI rating and canopy density, suggesting that consecutive loss of canopy (via thermotherapy or defoliation) resulted in accelerated decline of already diseased (HLB-affected) trees. Similarly, it has been reported that severe pruning of HLB-affected trees does not result in any significant improvement in health (Rouse et al., 2017; Vashisth and Gainey, 2017). Over the course of 2 years, all the trees in the experiment showed a decline in health, most likely owing to the HLB epidemic. All the treatments resulted in significant crop loss in the first year as well; however, yields were similar in year 2. Overall, we did not find in-field thermotherapy to be efficient in curing or boosting the health of HLB-affected trees. Our results also indicated that the brief
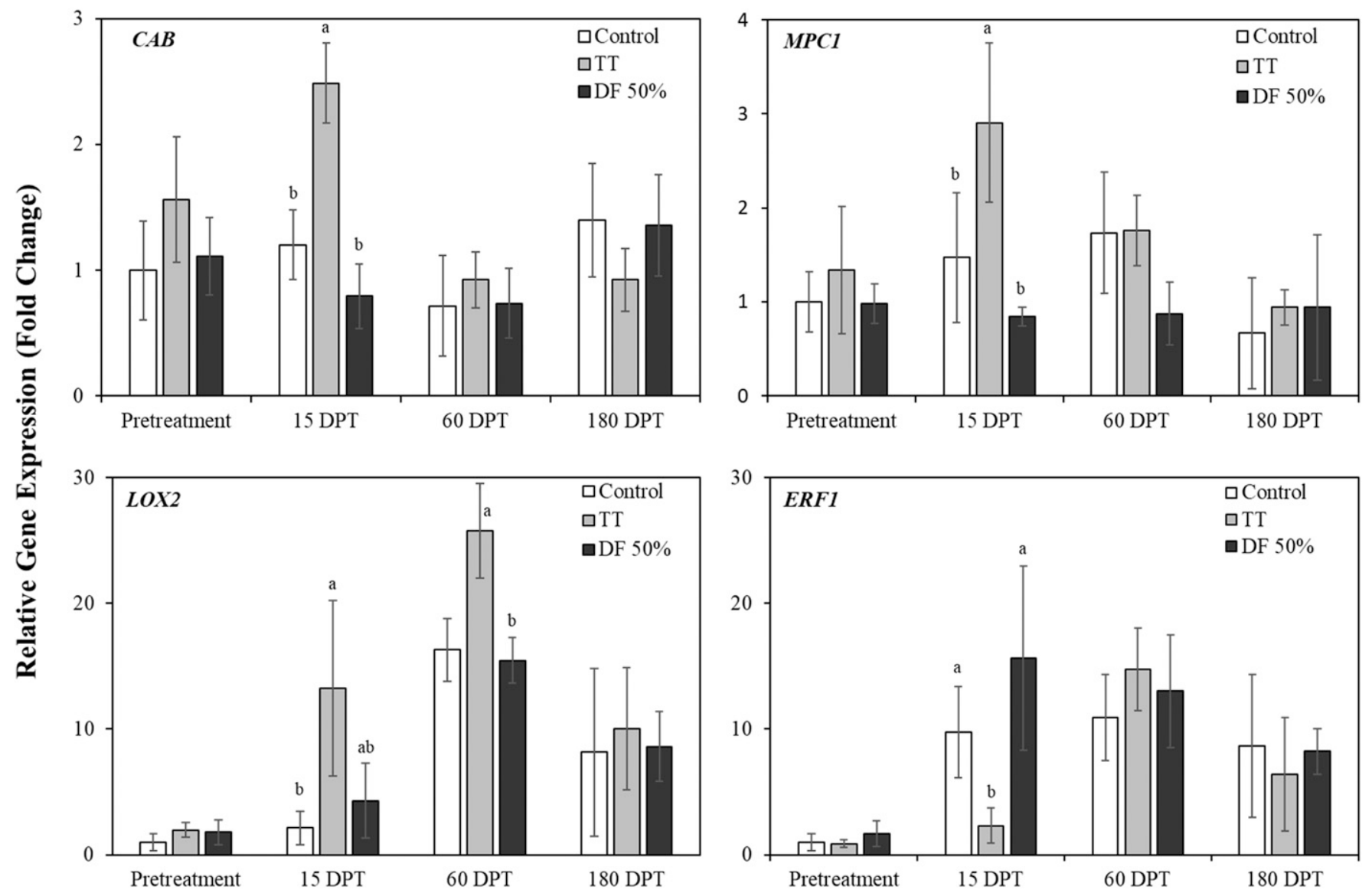

Fig. 1. Relative gene expression (average fold change) with standard deviation for $C A B, M P C 1, L O X 2, E R F$ in the leaf of 9-year-old 'Valencia' on Swingle trees at pretreatment, and 15, 60, and $180 \mathrm{~d}$ posttreatment (DPT). The treatments performed were Thermotherapy (TT), Defoliation 50\% (DF), and untreated control. Mitochondrial pyruvate carrier 1 (MPC1), Chlorophyll A-B binding family protein (CAB), Lipoxygenase 2 (LOX2), and Ethylene response factor (ERF). Bars marked with different lowercase letters indicate statistically significant differences within timepoint using Tukey's honestly significant difference test at $\alpha=0.05$. 
Table 5. Average concentration of glucose, fructose, sucrose, inositol, and total carbohydrate in leaves of 9-yearold 'Valencia' on Swingle trees at pretreatment, and 15, 60, and $180 \mathrm{~d}$ posttreatment (DPT). The treatments analyzed were as follows: Control (untreated), Thermotherapy (TT), and 50\% Defoliation (DF 50\%).

\begin{tabular}{|c|c|c|c|c|}
\hline \multirow[b]{2}{*}{ Treatment } & \multicolumn{4}{|c|}{ Glucose (mg/g fresh wt) } \\
\hline & Pretreatment & $15 \mathrm{DPT}$ & $60 \mathrm{DPT}$ & $180 \mathrm{DPT}$ \\
\hline Control & 1.89 & 1.41 & 1.79 & 1.62 \\
\hline TT & 1.75 & 1.47 & 1.90 & 1.71 \\
\hline DF $50 \%$ & 1.68 & 1.29 & 1.71 & 1.85 \\
\hline \multirow[t]{2}{*}{$P$ value } & NS & NS & NS & NS \\
\hline & \multicolumn{4}{|c|}{ Fructose $(\mathrm{mg} / \mathrm{g}$ fresh wt) } \\
\hline Treatment & Pretreatment & $15 \mathrm{DPT}$ & $60 \mathrm{DPT}$ & $180 \mathrm{DPT}$ \\
\hline Control & 1.70 & 1.40 & 1.56 & 1.51 \\
\hline TT & 1.8 & 1.42 & 1.59 & 1.35 \\
\hline DF $50 \%$ & 1.65 & 1.15 & 1.65 & 1.34 \\
\hline \multirow[t]{2}{*}{$P$ value } & NS & NS & NS & NS \\
\hline & \multicolumn{4}{|c|}{ Sucrose (mg/g fresh wt) } \\
\hline Treatment & Pretreatment & $15 \mathrm{DPT}$ & $60 \mathrm{DPT}$ & $180 \mathrm{DPT}$ \\
\hline Control & 6.1 & $5.16 b^{z}$ & 6.35 & 5.96 \\
\hline TT & 7.9 & $7.10 \mathrm{a}$ & 5.44 & 5.42 \\
\hline DF $50 \%$ & 6.5 & $6.11 \mathrm{ab}$ & 5.68 & 5.67 \\
\hline \multirow[t]{2}{*}{$P$ value } & NS & $<0.001$ & NS & NS \\
\hline & \multicolumn{4}{|c|}{ Inositol (mg/g fresh wt) } \\
\hline Treatment & Pretreatment & $15 \mathrm{DPT}$ & $60 \mathrm{DPT}$ & $180 \mathrm{DPT}$ \\
\hline Control & 0.49 & 0.51 & 0.66 & 0.37 \\
\hline TT & 0.42 & 0.59 & 0.65 & 0.36 \\
\hline DF $50 \%$ & 0.40 & 0.65 & 0.62 & 0.40 \\
\hline \multirow[t]{2}{*}{$P$ value } & NS & NS & NS & NS \\
\hline & \multicolumn{4}{|c|}{ Total carbohydrate (mg/g fresh wt) } \\
\hline Treatment & Pretreatment & $15 \mathrm{DPT}$ & $60 \mathrm{DPT}$ & $180 \mathrm{DPT}$ \\
\hline Control & 10.18 & $8.49 b^{z}$ & 10.38 & 9.46 \\
\hline TT & 11.87 & $10.56 \mathrm{a}$ & 9.58 & 8.84 \\
\hline DF $50 \%$ & 10.53 & $9.200 \mathrm{ab}$ & 9.66 & 9.27 \\
\hline$P$ value & NS & $<0.001$ & NS & NS \\
\hline
\end{tabular}

${ }^{\mathrm{z}}$ Means followed by different lowercase letters indicate statistically significant differences among treatments within timepoint using Tukey's honestly significant difference test at $\alpha=0.05$. NS $=$ not significant $(P>0.05)$.

healthy vegetative growth phase observed in trees following in-field thermotherapy is likely due to partial defoliation. As clearly demonstrated in this study, the thermotherapy treatment and partial defoliation (DF $50 \%$ ) had similar results for overall tree health throughout the course of the experiment. Nonetheless, some subtle transient differences were observed between thermotherapy and partial defoliation treatment. Thermotherapy-treated trees showed a significant increase for $M P C 1$ as compared with control and DF $50 \%$ on 15 DTP. Mitochondrial pyruvate carrier 1 (MPC1), is known to be involved in abscisic acid (ABA)-mediated drought response in Arabidopsis (Shen et al., 2017), it helps in mediating the effects of ABA accumulation by transporting cytosolic pyruvate to mitochondria, so that photosynthesis can occur uninterrupted (Li et al., 2014; Wang et al., 2014). Similar to MPC1, an upregulation for Chlorophyll $A-B$ binding family protein $(C A B)$ was observed in TT as compared with control and DF $50 \%$ on 15 DTP. These proteins are an integral part of the light-harvesting complex of photosystem II (PSII), which are normally complexed with chlorophyll and xanthophylls and serve as the antenna complex (Jansson, 1994, 1999). Several studies in Arabidopsis have demon- to be highly upregulated at 15 and 60 DPT in response to thermotherapy as compared with control. Many reports suggest the involvement of $L O X 2$ in jasmonic acid biosynthesis is a response to a wounding or herbivory (Bell et al., 1995; Bell and Mullet, 1993), plant defense (Rizhsky et al., 2002), and abiotic stress including heat stress (Ali et al., 2005; Rizhsky et al., 2002). LOX2 upregulation has been identified in HLB-affected citrus (Fan et al., 2011; Zheng and Zhao, 2013), most likely owing to its involvement in the plant defense response (Gardner, 1991; Siedow, 1991). This study reports that upregulation of Lipoxygenase in thermotherapy resulted in mitigating treatment-induced heat stress. Interestingly, Ethylene response factor $(E R F)$ was observed to be downregulated in thermotherapy trees as compared with control and DF $50 \%$ at 15 DPT. Overall, an increase (significant) in $E R F$ expression was seen in untreated trees (control) and DF 50\% as the time progressed in season. ERF is a downstream component of the ethylene-signaling pathway and is well known to be involved in plant defense response (Lorenzo et al., 2003). It is widely reported to be upregulated in HLB-affected citrus and downregulated in HLB-tolerant varieties of citrus (Kim et al., 2009; Mafra et al., 2013; Wang et al., 2016). $E R F$ 's downregulation in thermotherapy trees for a brief duration and increase in expression in all the trees (including control) as the season progressed suggests that thermotherapy treatment may have boosted plant defense or suppressed the pathogen briefly (Doud et al., 2017). However, this effect could not be maintained because of factors such as CLas movement from roots and reinfection via psyllid infestation, TT had same level of $E R F$ as control by $60 \mathrm{DPT}$.

Overall, our results indicate that in-field thermotherapy is not an effective and reliable strategy for HLB mitigation in commercial citrus production. The short-term effects of vigorous growth and vegetative flush are an artifact of partial defoliation induced by high heat treatment. Thermotherapy, or any other strategy resulting in canopy loss, can result in significant crop reduction for the subsequent year, making it a difficult choice in commercial production. Unless the thermotherapy can be applied to the whole tree, including the roots, and psyllid infestation can be minimized, the commercial success of in-field thermotherapy is likely to be limited. Under HLB-prevalent conditions, intensive grove management is essential, otherwise, the trees are prone to gradual decline, as seen in this study.

\section{Literature Cited}

that the stress induced-ABA accumulation interrupted the phloem loading of sucrose (Vreugdenhil, 1983), resulting in a shortlived increase of sucrose. However, we did not find differences in expression of Sucrose transporter (SUT) and other carbohydrate metabolism-related genes. This cannot predispose the possibility of changes happening before 15 DPT and stabilizing by and after 15 DPT. LOX2, Lipoxygenase 2, was observed
Ali, M.B., E.J. Hahn, and K.Y. Peck. 2005. Effects of temperature on oxidative stress defense systems, lipid peroxidation and lipoxygenase activity in Phalaenopsis. Plant Physiol. Biochem. 43:213-223

Alvarez, S., E. Rohrig, D. Solís, and M.H. Thomas. 2016. Citrus greening disease (huanglongbing) in Florida: Economic impact, management and 
the potential for biological control. Agr. Res. 5: 109-118.

Ananthakrishnan, G., N. Choudhary, A. Roy, V.G. Sengoda, E. Postnikova, J.S. Hartung, A.L. Stone, V.D. Damsteegt, W.L. Schneider, J.E. Munyaneza, and R.H. Brlansky. 2013. Development of primers and probes for genus and species-specific detection of 'Candidatus Liberibacter species' by real-time PCR. Plant Dis. 97:1235-1243.

Baker, R. 1962. Thermotherapy of planting material. Phytopathology 52:1244-1255.

Bell, E., R.A. Creelman, and J.E. Mullet. 1995. A chloroplast lipoxygenase is required for woundinduced jasmonic acid accumulation in Arabidopsis. Proc. Natl. Acad. Sci. USA 92:8675-8679.

Bell, E. and J.E. Mullet. 1993. Characterization of an Arabidopsis lipoxygenase gene responsive to methyl jasmonate and wounding. Plant Physiol. 103:1133-1137.

Bové, J.M. 2006. Huanglongbing: A destructive, newly-emerging, century-old disease of citrus. J. Plant Pathol. 1:7-37.

Cataldi, T.R., G. Margiotta, L. Iasi, B. Di Chio, C. Xiloyannis, and S.A. Bufo. 2000. Determination of sugar compounds in olive plant extracts by anion-exchange chromatography with pulsed amperometric detection. Anal. Chem. 72:3902-3907.

Doud, M., Y. Wang, M.T. Hoffman, C.L. Latza, W. Luo, C.M. Armstrong, T.R. Gottwald, L. Dai, F. Luo, and Y. Duan. 2017. Solar thermotherapy reduces the titer of Candidatus Liberibacter Asiaticus and enhances canopy growth by altering gene expression profiles in HLBaffected citrus plants. Hort. Res. 27:17-54.

Eckert, J.W. and A.F. Sommer. 1967. Control of diseases of fruits and vegetables by postharvest treatment. Annu. Rev. Phytopathol. 5:391-428.

Eissenstat, D.M. and L.W. Duncan. 1992. Root growth and carbohydrate responses in bearing citrus trees following partial canopy removal. Tree Physiol. 10:245-257.

Etxeberria, E., P. Gonzalez, D. Achor, and G. Albrigo. 2009. Anatomical distribution of abnormally high levels of starch in HLB-affected Valencia orange trees. Physiol. Mol. Plant Pathol. 74:76-83.

Fan, G.C., Y.L. Xia, X.J. Lin, H.Q. Hu, X.D. Wang, C.Q. Ruan, L.M. Lu, and L.I. Bo. 2016. Evaluation of thermotherapy against huanglongbing (citrus greening) in the greenhouse. J. Integr. Agr. 15:111-119.

Fan, J., C. Chen, Q. Yu, R.H. Brlansky, Z.G. Li, and F.G. Gmitter, Jr. 2011. Comparative iTRAQ proteome and transcriptome analyses of sweet orange infected by "Candidatus Liberibacter asiaticus". Physiol. Plant. 143:235-245.

Gardner, H.W. 1991. Recent investigations into the lipoxygenase pathway of plants. Biochim. Biophys. Acta 1084:221-239.

Graca, J.D. 1991. Citrus greening disease. Annu. Rev. Phytopathol. 1:109-136.

Grondeau, C., R. Samson, and D.C. Sands. 1994. A review of thermotherapy to free plant materials from pathogens, especially seeds from bacteria. CRC Crit. Rev. Plant Sci. 13:57-75.

Halbert, S.E. and K.L. Manjunath. 2004. Asian citrus psyllids (Sternorrhyncha: Psyllidae) and greening disease of citrus: A literature review and assessment of risk in Florida. Fla. Entomol. 87:330-353.

Hoffman, M.T., M.S. Doud, L. Williams, M.Q. Zhang, F. Ding, E. Stover, D. Hall, S. Zhang, L.
Jones, M. Gooch, and L. Fleites. 2013. Heat treatment eliminates 'Candidatus Liberibacter asiaticus' from infected citrus trees under controlled conditions. Phytopathology 103:15-22.

Jansson, S. 1994. The light-harvesting chlorophyll ab-binding proteins. Biochim. Biophys. Acta (BBA)-Bioenergetics 1184:1-19.

Jansson, S. 1999. A guide to the Lhc genes and their relatives in Arabidopsis. Trends Plant Sci. 4:236-240.

Johnson, E.G., J. Wu, D.B. Bright, and J.H. Graham. 2014. Association of 'Candidatus Liberibacter asiaticus' root infection, but not phloem plugging with root loss on huanglongbing-affected trees prior to appearance of foliar symptoms. Plant Pathol. 63:290-298.

Kim, J.S., U.S. Sagaram, J.K. Burns, J.L. Li, and N. Wang. 2009. Response of sweet orange (Citrus sinensis) to 'Candidatus Liberibacter asiaticus' infection: Microscopy and microarray analyses. Phytopathology 99:50-57.

Langdon, K.W., R. Schumann, L.L. Stelinski, and M.E. Rogers. 2018. Influence of tree size and application rate on expression of Thiamethoxam in citrus and its efficacy against Diaphorina citri (Hemiptera: Liviidae). J. Econ. Entomol. 111:770-779.

Larkindale, J. and M.R. Knight. 2002. Protection against heat stress-induced oxidative damage in Arabidopsis involves calcium, abscisic acid, ethylene, and salicylic acid. Plant Physiol. 128: 682-695.

Li, C.L., M. Wang, X.Y. Ma, and W. Zhang. 2014. NRGA1, a putative mitochondrial pyruvate carrier, mediates ABA regulation of guard cell ion channels and drought stress responses in Arabidopsis. Mol. Plant 7:1508-1521.

Li, J, L. Li, Z. Pang, V. Kolbasov, R. Ehsani, E. Carter, and N. Wang. 2019. Developing citrus Huanglongbing management strategies based on the severity of symptoms in HLB-endemic citrus-producing regions. Phytopathology 109: 582-592.

Lin, K.H. and H.H. Lo. 1981. A preliminary study on thermotherapy of yellow shoot disease of citrus. Acta Phytophyloacica Sinica 4:169175.

Liu, R., Y.H. Xu, S.C. Jiang, K. Lu, Y.F. Lu, X.J. Feng, Z. Wu, S. Liang, Y.T. Yu, X.F. Wang, and D.P. Zhang. 2013. Light-harvesting chlorophyll a/b-binding proteins, positively involved in abscisic acid signaling, require a transcription repressor, WRKY40, to balance their function. J. Expt. Bot. 6418:5443-5456.

Lo, X., D. Lo, and W. Tang. 1981. Studies on the thermotherapy of citrus yellow shoot disease. Acta Phytopathol Sin. 8:47-51.

Loescher, W.H., T. McCamant, and J.D. Keller. 1990. Carbohydrate reserves, translocation, and storage in woody plant roots. HortScience 25:274-281.

Lorenzo, O., R. Piqueras, J.J. Sánchez-Serrano, and R. Solano. 2003. Ethylene Response Factor1 integrates signals from ethylene and jasmonate pathways in plant defense. Plant Cell 151:165178.

Mafra, V., P.K. Martins, C.S. Francisco, M. RibeiroAlves, J. Freitas-Astúa, and M.A. Machado. 2013. Candidatus Liberibacter americanus induces significant reprogramming of the transcriptome of the susceptible citrus genotype. BMC Genomics 1:247.
Pfaffl, M.W. 2001. A new mathematical model for relative quantification in real-time RT-PCR Nucleic Acids Res. 29(9):e45.

Phillips, R.L. 1978. Hedging and topping citrus in high-density plantings. Proc. Annu. Meet. Fla. State Hort. Soc. 91:43-46.

Ramakers, C., J.M. Ruijter, R.H. Deprez, and A.F. Moorman. 2003. Assumption-free analysis of quantitative real-time polymerase chain reaction (PCR) data. Neurosci. Lett. 339:62-66.

Rizhsky, L., H. Liang, and R. Mittler. 2002. The combined effect of drought stress and heat shock on gene expression in tobacco. Plant Physiol. 130:1143-1151.

Rosales, R. and J.K. Burns. 2011. Phytohormone changes and carbohydrate status in sweet orange fruit from huanglongbing-infected trees. J. Plant Growth Regul. 30:312-321.

Rouse, R.E., M. Ozores-Hampton, F.M. Roka, and P. Roberts. 2017. Rehabilitation of huanglongbing-affected citrus trees using severe pruning and enhanced foliar nutritional treatments. HortScience 52:972-978.

Ruijter, J.M., C. Ramakers, W.M. Hoogaars, Y. Karlen, O. Bakker, M.J. Van den Hoff, and A.F. Moorman. 2009. Amplification efficiency: Linking baseline and bias in the analysis of quantitative PCR data. Nucleic Acids Res. 37(6): 45 .

Savage, Z. 1960. Citrus yield per tree by age. Citrus Ind. 41:20-22.

Schneider, H. 1968. Anatomy of greening-diseased sweet orange shoots. Phytopathology 58:11551160 .

Schumann, A. and A. Singerman. 2016. The economics of citrus undercover production systems and whole tree thermotherapy. Citrus Ind. 97:14-18.

Shen, J.L., C.L. Li, M. Wang, L.L. He, M.Y. Lin, D.H. Chen, and W. Zhang. 2017. Mitochondrial pyruvate carrier 1 mediates abscisic acidregulated stomatal closure and the drought response by affecting cellular pyruvate content in Arabidopsis thaliana. BMC Plant Biol. 17:217.

Siedow, J.N. 1991. Plant lipoxygenase: Structure and function. Annu. Rev. Plant Biol. 42:145188.

Vashisth, T. and T. Gainey. 2017. Pruning to rehabilitate HLB-affected sweet oranges. Citrus Ind. 97:18-23.

Vreugdenhil, D. 1983. Abscisic acid inhibits phloem loading of sucrose. Physiol. Plant. 57:463-467.

Wang, M., X. Ma, J. Shen, C. Li, and W. Zhang. 2014. The ongoing story: The mitochondria pyruvate carrier 1 in plant stress response in Arabidopsis. Plant Signal. Behav. 9:e973810.

Wang, Y., L. Zhou, X. Yu, E. Stover, F. Luo, and Y. Duan. 2016. Transcriptome profiling of Huanglongbing (HLB) tolerant and susceptible citrus plants reveals the role of basal resistance in HLB tolerance. Front. Plant Sci. 28:933.

Xu, Y.H., R. Liu, L. Yan, Z.Q. Liu, S.C. Jiang, Y.Y. Shen, X.F. Wang, and D.P. Zhang. 2011. Lightharvesting chlorophyll a/b-binding proteins are required for stomatal response to abscisic acid in Arabidopsis. J. Expt. Bot. 63:1095-1106.

Zheng, Z.L. and Y. Zhao. 2013. Transcriptome comparison and gene coexpression network analysis provide a systems view of citrus response to 'Candidatus Liberibacter asiaticus' infection. BMC Genomics 14:27. 


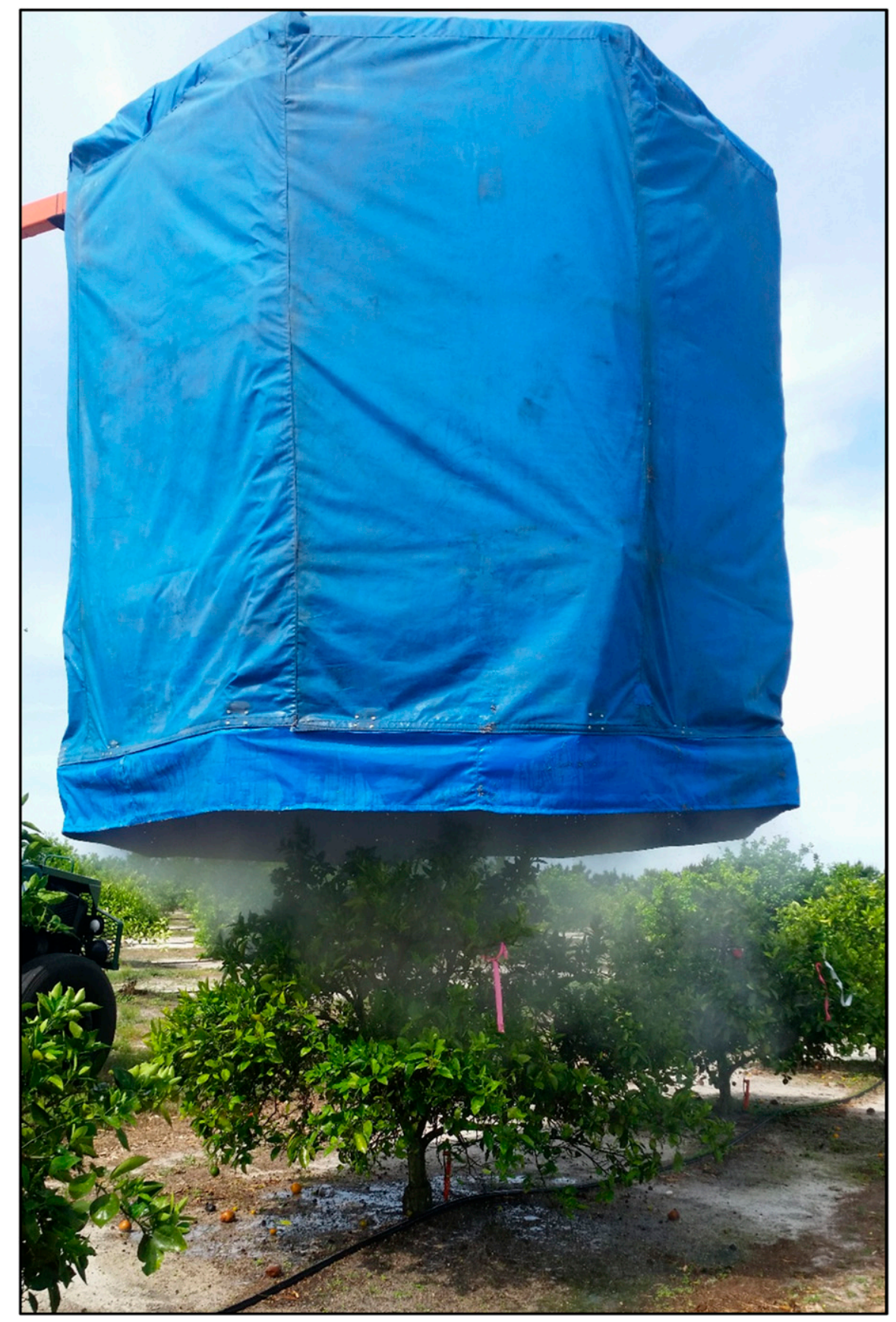

Supplemental Fig. 1. Thermotherapy in process, the tent equipped with steam and fans used to in-field thermotherapy the Huanglongbing-affected 'Valencia' on Swingle trees at $55^{\circ} \mathrm{C}$ for $3 \mathrm{~min}$. 


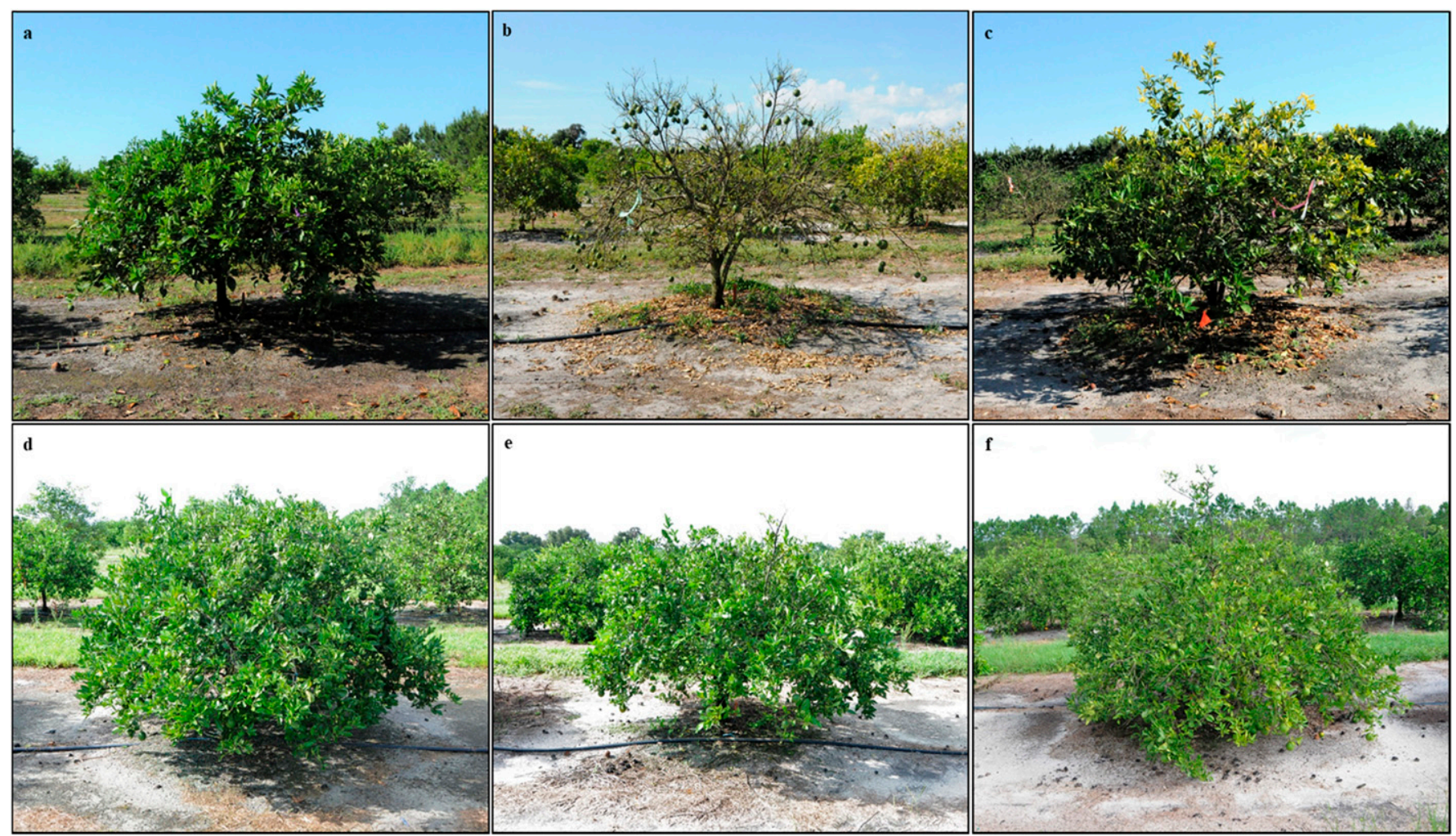

Supplemental Fig. 2. Control (A), 100\% Defoliated (B), and Thermotherapy-treated (C) trees at $7 \mathrm{~d}$ after treatment. (D-F) Control (D), $100 \%$ Defoliated (E), and Thermotherapy-treated (F) after 2 years of treatment. 